\title{
Los miedos en tiempos de crisis según docentes y estudiantes de Argentina
}

\author{
The fears in times of crisis according to teachers \\ and students of Argentina
}

\author{
Eduardo Langer \\ Investigador Adjunto Conicet UNSAM/UNPA \\ langereduardo@gmail.com \\ Código Orcid: https://orcid.org/0000-0001-7946-7129
}

\begin{abstract}
Resumen
En este artículo se propone trabajar sobre los sentidos que docentes y estudiantes de escuelas secundarias en contextos de pobreza urbana del conurbano de Buenos Aires (Argentina) dan a los miedos en tiempos de crisis. El objetivo es caracterizar las tensiones de esos sentidos entre miedos y esperanzas de adultos y jóvenes, dentro y fuera de la escuela. El interrogante que se propone trabajar es cómo y por qué a pesar de (sobre) vivir en una sociedad en crisis y que produce múltiples miedos, tanto docentes como estudiantes otorgan valor y utilidad a la escuela, tienen esperanzas en la formación y en el futuro. Se propone abordar esta pregunta en el marco de una investigación en la cual se realiza una propuesta metodológica múltiple en la que se realizan entrevistas y observaciones en profundidad con estudiantes y docentes, producciones audiovisuales en una escuela secundaria y por último a través de resultados de una acción de extensión en la que se trabaja con todas las escuelas secundarias del partido de San Martín. Los resultados que el artículo muestra es que a pesar de los miedos, las incertidumbres y la desorientación que, muchas veces, parece imperar en la escuela, hay docentes y estudiantes que además tienen esperanzas, deseos, sueños y proyectos aún en condiciones que no dejan lugar para ello.
\end{abstract}

Palabras clave

Miedos, crisis, escuela, profesores, estudiantes, pobreza.

Forma sugerida de citar: Langer, Eduardo (2018). Los miedos en tiempos de crisis según docentes y estudiantes de Argentina. Universitas, 28, pp. 19-38. 


\begin{abstract}
This paper address the meanings and the sense that secondary teachers and students of urban poverty schools in the suburbs of Buenos Aires (Argentina) assign to their fears in times of crisis. The goal is to describe the tensions between fear and hopes contained in those meanings and senses, whether inside or outside of the school context. The central question of this paper is how and why, despite living -and surviving-in a state of societal crisis which produces many fears in people, both teachers and students value the school as useful, and have hopes about their education and training, and also about their future. The paper answers to this question within the framework of a multiple research methods process which includes interviews and in-depth observations to students and teachers; audiovisual productions in a secondary school; and action and intervention with all secondary schools of the San Martin District of Buenos Aires. The results of the discussion are that in spite of the fears, the uncertainty, and the disorientation that seems to prevail in the school; teachers and students also have hopes, wishes, dreams, and projects, even in conditions where it seems there is no place for them.
\end{abstract}

\title{
Keywords
}

Fears, crisis, school, teachers, students, poverty.

\section{Introducción}

"Miedo a la multitud, miedo a la soledad, miedo a lo que fue y a lo que puede ser, miedo de morir, miedo de vivir" (Galeano, 2010).

Galeano (2010) describe el miedo global, a la multitud y a la soledad, a lo que fue y lo que será, el miedo de morir y de vivir, el miedo de los que trabajan a perder el trabajo y los que no trabajan de no encontrar nunca trabajo. Estamos y vivimos en "tiempos de miedo" (Bauman, 2014, p. 11) y en una sociedad que se produce a través del miedo de los otros, de los de afuera y de los de adentro, que varía en función de los miedos de antes y de los que pueden venir.

En este artículo se propone trabajar sobre los sentidos que docentes y estudiantes de escuelas secundarias en contextos de pobreza urbana del conurbano de Buenos Aires (Argentina) dan a los miedos en tiempos de cri- 
sis $^{1}$. Los miedos son aquellos con que se enfrentan los sujetos tanto fuera como dentro de la escuela y a la vez motorizan las esperanzas en el mundo en general y en el de la educación en particular. Si el miedo paraliza, inmoviliza y detiene, aquí sostenemos que también moviliza, genera y produce. La hipótesis central que desarrollaremos es que a pesar de la incertidumbre y de la desorientación que, muchas veces, parece imperar en la escuela, las contradicciones $^{2}$ políticas y normativas, las idas y vueltas, los temores, angustias y pérdidas, nos encontramos con docentes y estudiantes que además de hablar sobre y tener miedos también tienen esperanzas, deseos, sueños y proyectos aún en condiciones que no dejan lugar para ello. Desde los sentidos que ofrecen cotidianamente los estudiantes y los docentes, la escuela continúa siendo un espacio de interpretación e integración, de estructuración de proyectos y expectativas de vida. Allí pueden pensar y se piensan recurriendo a sentimientos tales como el amor, la soledad y la angustia que produce encontrarse reiteradamente con caminos sin salidas o con las miradas negativas de los otros. Este artículo propone caracterizar las tensiones que se encuentran en esos sentidos, en los relatos de sus dificultades y de sus esperanzas dentro y fuera de la escuela.

Los sentidos que aquí se describen son considerados como no individuales ni personales, tal como dice Deleuze (1994), sino que son las emisiones de las singularidades que son los verdaderos acontecimientos trascendentales y que presiden la génesis de los individuos y de las personas, así el sentido "sería entonces irreductible a los estados de cosas individuales, y a las imágenes particulares, y a las creencias personales, y a los conceptos universales y generales" (p. 20). Aquí nos detenemos en los desplazamientos de los sentidos (Barthes, 1981), es decir, esos sentidos en sus dinámicas específicas en las escuelas que expresan las creencias personales y generales sobre los miedos y las valoraciones en tiempos de crisis, exclusión y/o de desocupación. Si las personas son quienes experimentan los miedos, es la

1 Cuando hacemos mención a la noción de crisis pensamos efectivamente en los períodos de crisis de Argentina como lo fue, por ejemplo, el 2001 y también tomamos la noción en términos amplios para pensar en las transformaciones sociales, económicas, laborales y educativas que se vienen desarrollando en el país hace algunas décadas.

2 Nos referimos a las desorientaciones y contradicciones producto de las sucesivas reformas educativas del país en los 70, 80, 90 y 2000 y que dejan a los sujetos en situaciones de fragilidad y soledad. Para un desarrollo de estas desorientaciones y contradicciones que se desarrollan en el sistema educativo (ver Grinberg y Langer, 2014). 
sociedad la que los construye y genera unos modos de respuesta estandarizada según los diferentes periodos históricos. Por ello, según Reguillo (2000), los miedos son siempre una experiencia individualmente experimentada, socialmente construida y culturalmente compartida.

Algunas de las respuestas que aquí se trabajarán se dirigen, retomando a Deleuze (2005), a las potencias de vida y a los modos de habitar y estar, los sentidos sobre los miedos, las preocupaciones, los temores así como los deseos de los sujetos en condición de pobreza. El interrogante central que se propone trabajar es cómo y por qué a pesar de (sobre) vivir en una sociedad en crisis, sin trabajo o con trabajos muy precarios, y a pesar de existir miedos profundos en estas condiciones, tanto docentes como estudiantes otorgan valor y utilidad a la escuela, tienen esperanzas en la formación y en el futuro que puede llegar a venir. Se propone abordar esta pregunta en el marco de una investigación ${ }^{3}$ en la cual se realiza una propuesta metodológica cualitativa y múltiple en la que se realizaron entrevistas en profundidad a docentes y estudiantes del nivel secundario, así como observaciones en un taller audiovisual ${ }^{4}$ que se viene realizando desde el 2008 a la actualidad en una escuela secundaria del Partido de San Martín y por último a través de resultados de una acción de extensión en la que se trabaja con todas las escuelas secundarias del partido de San Martín ${ }^{5}$.

3 En el marco del CEDESI (Centro de Estudios sobre Desigualdad, Sujetos e Instituciones) de la Universidad Nacional de San Martín, Provincia de Buenos Aires, Argentina se realizaron entrevistas a estudiantes y docentes de ocho escuelas secundarias según criterios de georreferencia y en función de un índice de vulnerabilidad socio geográfico de las escuelas desde 2011 hasta la actualidad.

4 El taller "es un espacio que tiene como objetivo la producción de audiovisuales por parte de estudiantes con el fin de propiciar situaciones de pensamiento y problematización de la realidad a través de la realización documental, a la vez que generar debates e intercambios de las problemáticas barriales en el espacio escolar" (Carpentieri, Dafunchio, Langer, Machado, 2015, p. 1). El taller se realiza desde 2008 a la actualidad, una vez por semana, con estudiantes del nivel secundario de entre 12 y 19 años de una escuela que se sitúa a pocas cuadras de dos villas miseria del Área Metropolitana de Buenos Aires y que en cada año se finaliza con la producción de cortos documentales. Aquí se traen a colación algunos breves retazos de alguno de ellos.

5 Nos referimos a la Feria de Ciencias Humanas y Sociales y al Festival de Cortos Audiovisuales para todas las escuelas secundarias del Partido de San Martín organizada por la Universidad Nacional de San Martín, las cuales me encuentro coordinando. Para más información ver http://www.unsam.edu. ar/escuelas/humanidades/I-Feria/ 


\section{Estado de la cuestión sobre los miedos en tiempos de crisis}

Nos referimos a los miedos en tiempos de crisis focalizando la atención en contextos de pobreza urbana que se desarrollan por el surgimiento de asentamientos y villas miserias ${ }^{6}$. Allí la precariedad de la tenencia de la vivienda es la norma que impera desde las últimas décadas del siglo XX. Ello porque las estadísticas demuestran que las peores víctimas y afectados por los múltiples procesos de violencia y, por tanto, por los miedos que se generan, son los pobres. Aún más expuestos que nadie son los jóvenes habitantes de barrios marginales (Rotker, 2000). Los barrios en los que se desarrolla la presente investigación ${ }^{7}$ y las acciones de extensión, crecieron al calor de los procesos de pauperización y precarización de la población "liminar" (Foucault, 2006) que no es exclusiva de nuestro territorio sino de todas las grandes urbes de América Latina.

Este tipo de miseria no es nueva. Tampoco lo es la relación entre pobreza y miedo. De hecho Duby (1995) relata su aparecimiento hacia el siglo XII en los suburbios de ciudades donde se amontonan "los desarraigados" (p. 25) y cómo se forma el miedo a ella. Pero lo que no existía es "la espantosa soledad del miserable que vemos en nuestros días" (p. 27) por ciertos mecanismos de ayuda que evitaron, en esa sociedad, la miseria terrible que hoy conocemos. No existía la exclusión de una parte de la sociedad, "se era muy pobre, pero junto con los demás" (Duby, 1995, p. 28). A la vez, la escasez era para los gobiernos el acontecimiento que debía evitarse centralmente por una serie de razones, pero la más importante era la revuelta (Foucault, 2006).

Hoy ello entra en tensión y la cuestión es que los gobiernos, sea de Argentina como de casi cualquier otra parte de la región latinoamericana, ya no impiden la escasez, ya no la detienen, no la erradican ni la previenen. Si ya no se impide el hecho más temido que es que la gente se rebele, con Foucault (2006) nos preguntamos “¿Cómo son las cosas (...) cuando se intenta desmontar ese sistema?" (p. 50). Los miedos actuales señalan y hacen responsable a los que se rebelan, a través de ellos se culpabiliza al "pobre" por

6 Es una forma que en Argentina se utiliza para denominar a territorios degradados en los que los servicios de luz, agua, cloaca y gas son muy precarios así como la construcción de las viviendas que allí se van instalando.

7 Para un desarrollo más exhaustivo del lugar de la investigación que se realiza, ver Langer (2016). 
su destino. Por tanto, hay un traslado de los miedos de los gobernantes a los propios sujetos. Si en las sociedades antiguas los ricos tuvieron miedo de los pobres porque eran demasiado numerosos e inquietantes (Duby, 1995, p. 46), hoy se sobrepasó ese umbral. ¿Qué sucede en la actualidad? En todo caso, este artículo trata de describir esas transformaciones desde el nivel de los discursos en el mundo de la escuela y cómo esos cambios tienen como estrategia amedrentar, es decir "infundir miedo, tomar medidas ejemplificadoras, intimidar. Actuar, como se dice con términos tan expresivos, sobre la población blanco, que es móvil, disgregable, incierta, y que algún día podría llegar a ser inquietante: jóvenes desocupados, estudiantes universitarios, estudiantes secundarios" (Foucault, 2012, p. 205). Aquí cobra relevancia la relación crisis, miedos y escolaridad desde esta perspectiva teórica. En todo caso, describir los miedos en la actualidad nos permite comprender los nuevos modos de habitar el mundo en general y la escuela en particular, son expresión de una angustia cultural generalizada que proviene de varios factores (Barbero, 2000) que sintetizaremos a continuación algunos de ellos.

La existencia de los miedos a los peligros internos y permanentes de la sociedad, como la delincuencia o los crímenes, siguiendo a Foucault (2014), es una de las condiciones de aceptabilidad del sistema de control. Por tanto, ello explica por qué en los medios de comunicación se concede tanto espacio como si se tratase de una novedad cada nuevo día. Así, el miedo se produce y se actualiza en el acontecimiento mismo del ejercicio del poder (Useche Aldana, 2012). De hecho, los regímenes políticos han recurrido al miedo como instrumento de dominación de los grupos privilegiados sobre los relegados (Korstanje, 2010). La hipótesis es que una sociedad con miedo es plausible de ser dominada, implica sumisión, exclusión e injusticia.

¿Qué es el miedo? Siguiendo a Bauman (2014), miedo es incertidumbre de lo porvenir, incluso para Useche Aldana (2012) agudiza el deterioro de los modos de convivencia, se traduce en una degradación acelerada y generalizada del tratamiento de los conflictos entre seres humanos, lleva a desconfiar de todo y de todos, establece un amplio campo del sin-sentido, puede expresarse en la incubación de estallidos violentos. El miedo es una fuerza que dramatiza las pasiones, que obstaculiza o potencia las formas de actuar, fractura o consolida la confianza, dificulta reconocer al otro y a las relaciones sociales de solidaridad. El miedo, para Croce (2005), es un mecanismo cuya principal consecuencia es "paralizar", se trata de "no moverse" de la 
situación en la que encuentra, "el miedo es un mecanismo muy poderoso respecto del accionar de las personas" (p. 84).

El miedo en las sociedades actuales, sobre todo cualquiera de las grandes urbes latinoamericanas, se manifiesta en la extensa capilaridad del cuerpo social a través de "los miedos a ser pobre, a quedar excluido, perder la vida, llegar a desemplearse o estar enfermo por epidemias emergentes, quizás a no contar con su familia o la desaparición de sus padres, en fin hay diversos miedos" (Salazar Pérez, 2011, p. 25). Se teme a la vejez y a la juventud, al hombre y a la mujer, a la violencia y a la paz, la muerte y la vida, al hambre, las multitudes y las soledades. Vivimos en un mundo que promueve el miedo y los Estados son agentes proactivos que se trasladan en esa nave (Salazar Pérez, 2011). Este miedo social justifica la mirada de peligrosidad (Kaplan, 2012), fundamentalmente de los jóvenes en condición de pobreza. De ahí que uno de los miedos centrales es, justamente, no poder controlar las energías de la juventud que opera como telón de fondo tanto fuera como dentro de la escuela.

Es desde aquí que sostenemos que la producción de una sociedad con miedos en la actualidad se desarrolla de la mano de los procesos de crisis laborales, económicos, políticos, sociales y, también, educativos. Nos referimos a la crisis de la sociedad en general y también de la crisis de la sociedad salarial en particular en toda la región. Estas crisis conllevan transformaciones: la destrucción de la idea del mundo del trabajo como elemento integrador de la vida, la desprotección e inseguridad o de una cuestión social a una cuestión de inseguridad (Castel, 2004), cambios subjetivos e identitarios de los sujetos hacia el "nada a largo plazo" (Sennett, 2000, p. 64). Las crisis nos agitan, nos dislocan, nos empujan, nos sujetan, trastocan nuestra vida y, por si fuera poco, nos hacen sentir culpables de "nuestro fracaso" (Sennett, 2000). En este marco, los miedos y las incertidumbres de los jóvenes y de los adultos es un dato permanente de la problemática para entender el proceso de desplazamiento de la conflictividad social hacia los mismos individuos. Esos miedos, sostenemos como hipótesis, se despliegan con mayor fuerza en los sistemas educativos de toda la región porque es desde donde hay que dar respuestas a una población que es segunda o tercera generación desocupada y que a la vez posiblemente nunca pueda tener acceso a un empleo estable.

Por tanto, aquí se propone describir las formas que adquieren los miedos en la cotidianeidad escolar y los sentidos que desde allí expresan esperanza para quebrar los destinos inexorables en contextos de pobreza urbana. Des- 
de nuestra perspectiva, los miedos liberan, siguiendo a Reguillo (2000), un tipo de energía que tiende a constituir una defensa frente a la amenaza percibida, reaccionan ante esas amenazas a través de esperanzas diferenciales en los sujetos. Por tanto, no hay miedo sin esperanza, ni esperanza sin miedo (Useche Aldana, 2012). De hecho, ya Spinoza (1980) había definido el miedo en relación con la esperanza. No creemos que, tal como dice Bauman (2014), los miedos se apoderan en su totalidad de las expectativas. Sin duda, los sujetos en condición de pobreza enfrentan las humillaciones en las que viven (Benjamin, 1987). En este sentido, los miedos no son solamente una forma de sentir y hablar sobre el mundo, es además una forma de actuar (Reguillo, 2000) porque a cada miedo se producen unas respuestas. A través de los miedos, la población actúa con cautela en su futuro y aferrados a signos del pasado (Salazar Pérez, 2011).

Por ello, desalojar los miedos implica acciones, relaciones e interacciones de intercambio, de confrontación, de escucha tal como es la que vamos a describir entre docentes y estudiantes en el cotidiano escolar. Sostenemos, que estas relaciones e intercambios se convierten en asunto político. Las posibilidades de compartir los miedos entre docentes y estudiantes conllevan palabras políticas para ir más allá de los determinismos que las condiciones y los lugares de vida van marcando. Volver visible la dimensión política del miedo, como dice Reguillo (2000), es asunto crucial en nuestros días porque, tal como seguimos a continuación, muchas veces funcionan como posibilidades para pensar en lo que viene. Es allí donde la escuela deviene en un lugar donde tanto jóvenes como adultos pueden pensar y problematizar sus vidas, pueden ponerles palabras y tener esperanzas hacia adelante.

\section{Análisis de resultados: los sentidos sobre los miedos en las escuelas}

La obligatoriedad del nivel secundario en Argentina es un derecho que se expande hacia los sectores populares durante la última década, específicamente con la nueva reforma educativa realizada en el $2006^{8}$. Es decir, entran sectores que antes no ingresaban a la escuela. Y en una sociedad que está sobresensibilizada por las problemáticas de la violencia o la inseguridad, si-

8 Nos referimos a la Ley de Educación Nacional No 26.206 de 2006. 
guiendo a Croce (2005), los miedos se desplazan hacia el sistema educativo porque los prejuicios llevan a concebir a estos jóvenes que son primera generación de ingresantes como potenciales delincuentes. Se produce "el miedo por las consecuencias institucionales de la inclusión. Muchos directivos tienen miedo de que la inclusión de jóvenes con problemas pueda hacer que chicos buenos dejen la escuela o que algunos padres de familias buenas reaccionen contra su falta de autoridad" (Croce, 2005, p. 85). Sin duda, el "temor a la exclusión" es un proceso global (Bauman, 2014, p. 31) y es desde allí que el mandato por la inclusión en la escuela secundaria, como receta que provienen de los organismos internacionales para los países en desarrollo como los latinoamericanos, se suma a la nave de miedos en tiempos de crisis. Ello quizás sea una de las principales y permanentes discusiones que se desarrollan en las escuelas, aún más cuando enfrentan períodos de reforma educativa, tal como lo formula un director:

Yo no le tengo miedo a la crisis. Al contrario, la crisis te produce desafíos de ¿cómo supero la crisis? Si está todo estanco, no creas nada. Aplicas siempre el mismo jueguito, la misma táctica y da el mismo resultado. No creas, la crisis te hace crear. No tengo miedo a hablar de que la escuela está en crisis. Si es para crecimiento, bienvenida la crisis. Yo no tengo miedo a la crisis. Hemos hecho un cambio acá en una escuela de economía, y ahora tiene economía, naturales, comunicación, con una transformación en materias, docentes que cambiaron de carga horaria y de materias y siguen estando en la escuela. Y el miedo era de perder el laburo. Estaban adentro (Director, escuela secundaria, José León Suárez, San Martín, Provincia de Buenos Aires, Mayo de 2014).

La primera asociación, tal como venimos insistiendo, es entre los miedos y las crisis. Inmediatamente, el director piensa su superación. Percibe y vive la crisis de la escuela, pero a la vez la piensa como desafío a través de la creatividad y de la transformación de lo que estaba. En todo caso, este es el argumento de este texto, justamente, la asociación miedos, crisis y las posibilidades de superación a través de las esperanzas, las respuestas, las acciones de los sujetos en las escuelas. En la formulación de los miedos, siguiendo a Reguillo (1996), se sucede con nitidez desde el discurso del director la oposición entre el antes y el ahora. Desde este sentido, no hay distinción entre el adentro y el afuera de la escuela que, en contraste, sí se sucede al indagar con jóvenes sobre aquello que define y constituyen los miedos actuales. 
Ellos “se van" fuera de la escuela para poder explicarlos, tal como aparecen en estos dos registros de observación:

[Un estudiante escribe en primer lugar la palabra "miedos" en el pizarrón, en la parte central del mismo. Luego va escribiendo aquello que lo define y constituye]: "crisis económicas, delito, calle, futuro, muerte, enfermedades, trabajo, desastres naturales, problemas familiares" (Registro de observación, escuela secundaria, Villa Ballester ${ }^{9}$, San Martín, Provincia de Buenos Aires, Agosto de 2017).

El joven ubica a los miedos en términos externos a la escuela. Son anteriores a ella, pero los piensa desde la institución. Aquello que le genera más miedo de todo lo que escribió en el pizarrón son las crisis económicas, tal como él lo dice:

Las crisis económicas porque nos podemos quedar en la pobreza y al quedarnos en la pobreza tendríamos que empezar a vivir en la calle, no tendríamos un futuro, habrían muchas enfermedades, no hubiese trabajo, tuviésemos muchos problemas familiares porque al generar pocas cosas va a haber problemas con la gente que lo quiere y lo que no quiere. Lo que más miedo me da son las crisis económicas. Lo que me genera menos miedo es la muerte. A todas las personas en algún momento les llega. Eso es lo que menos miedo me da (Estudiante, varón, Villa Ballester, San Martín, Provincia de Buenos Aires, agosto de 2017).

Así como el director de la cita anterior hacía la asociación miedos y crisis, aquí el estudiante manifiesta la misma relación justificando cómo con las crisis aquello que se produce es más pobreza, menos futuro, menos trabajo y más problemas familiares. Y ello lo contrapone a algo natural como la muerte. Algo que a todos en algún momento les puede pasar. Los miedos se producen ante las crisis porque es algo no natural y que, en todo caso, se puede evitar. Los jóvenes así como los docentes tratan de desnaturalizar los miedos, las crisis y sus formas de estar en el mundo y en la escuela.

A través de esas formas de desacralizar lo abyecto y desnaturalizar lo natural, en los jóvenes de otra escuela se propusieron como objetivo reconocer en el espacio urbano local las transformaciones materiales producto de

9 Si bien esta escuela está ubicada en Villa Ballester, lugar donde vive una población que puede ser considerada de sectores socioeconómicos medios, la escuela recibe población que se traslada desde la periferia, tal es así el estudiante que piensa sobre los miedos de la cita. 
los cambios económicos, sociales y culturales en el contexto de las crisis de las últimas décadas hasta la actualidad. Allí, los estudiantes identificaron los sitios decadentes, los nuevos y los refuncionalizados y pensaron esos contextos a través de la: "Falta de trabajo, desintegración, preocupación, falta de oportunidad, desigualdad, discriminación, diferencia de clases" (Registro de observación de clase, escuela secundaria, Loma Hermosa, San Martín, Provincia de Buenos Aires, Septiembre de 2017).

Nuevamente, el eje lo ubican en las variables estructurales que hacen y producen desigualdad en la sociedad actual y que ellos viven cotidianamente. Son jóvenes que viven los efectos de la quiebra de gran parte de las fábricas de la zona. El partido de San Martín, denominada "la ciudad de la industria", se desarma y son las familias de los jóvenes y ellos mismos que lo sufren y están siendo afectados por esos procesos. La desocupación, la subocupación y la ocupación en condiciones flexibilizadas, provocó el deterioro de los barrios obreros y el crecimiento de asentamientos precarios, contribuyendo a la gentrificación (Glass, 1964) de estos lugares. De esta forma, los miedos afloran, desde estos sentidos, más que con la reducción del Estado es con su transformación en las formas de gobierno y la pérdida de centralidad que en la sociedad tenía el ente público (Salazar Pérez, 2011, p. 31). El mercado no usurpa el papel del Estado, sino que este le da mayor lugar a aquel y así alimenta la fuente de la incertidumbre y de miedo que va marcado como huella de código de barras en los sujetos del siglo XXI. En este marco se producen las relaciones entre docentes y estudiantes, signadas por los miedos de unos a otros, por los miedos a los otros, por los miedos de lo que puede llegar a suceder, tal como un profesor dice:

Los chicos perciben cómo nos levantamos, cómo estamos, cómo hablamos, si titubeamos... Ellos... Como los perros. ¿Viste que un perro te ataca cuando percibe que vos tenés miedo? Bueno, los chicos son un poco así. Ellos perciben todo eso. Cómo te movés en el aula. Cuánto tardas en sacar tus cosas de adentro de la valija, cuánto tardas en escribir el libro de temas. Vos le estás dando mayor posibilidad al chico de hacer lo que quiera. O sea, son cosas que vos como docente tenés que administrar. Tu tiempo, el tiempo de ellos, el conocimiento que vos querés transmitir (Profesor, escuela secundaria, José León Suárez, San Martín, Provincia de Buenos Aires, Agosto 2016).

Así, la escolaridad se desarrolla en constante tensión entre los miedos pasados, presentes y futuros. Los miedos dan cuenta de los enfrentamientos 
más que de los encuentros en el aula. Justamente, la tensión cotidiana es entre ese "hacer lo que quiera" del estudiante y cómo "querés transmitir el conocimiento" del docente. Los miedos y/o temores quizás sean el centro de lo que allí sucede, de la escolaridad en la actualidad en contextos de pobreza urbana. Es así que un grupo de estudiantes les pregunta a un grupo de sus profesores “¿Cuáles eran tus temores en la adolescencia?”. Ante esa pregunta sucede que los profesores les relatan sobre sus temores, pero a la vez les hablan y dan ejemplo a sus estudiantes. Saben que los están escuchando y a la vez produciendo un corto ${ }^{10}$. Allí ya no hay enfrentamiento sino encuentro. Uno de los profesores les responde:

Hoy probablemente los temores son otros. (...) Siempre existe el miedo de tomar decisiones. No es tan fácil decir... bueno de respetar los sueños. De respetar lo que uno siente. Encontrar lo que uno siente, no es fácil. No es para nada fácil tomar una decisión. Y decir qué voy a hacer con mi vida. (...) Muchas veces uno tiene miedo de lanzarse a hacer determinadas cosas. Y a veces hay que vencerlo. (...)Creo que uno tiene que tratar de no tener miedo. De respetar sus propios deseos, de jugarse por algo que creen que vale la pena y eso es muy importante porque cuando a uno le quitan esa posibilidad entonces nos sacan la posibilidad de tener una buena vida (Profesor, escuela secundaria, Villa Maipú, Partido de San Martín, provincia de Buenos Aires, Septiembre de 2016).

Contextualiza a los miedos en primer lugar. Y luego, habla de los temores que él tenía en su adolescencia. Los temores a tomar decisiones o a respetar los sueños. Inmediatamente, ubica la superación o la posibilidad de ir más allá de ellos para tener una buena vida. Y son justamente esos modos de vida que dan cuenta de las formas generales y no de situaciones individuales o particulares, las condiciones a las que los docentes y estudiantes están acostumbrados a vivir y lidiar todos los días de su vida en contextos de pobreza urbana. Si bien podríamos pensar que en algún grado se constituyen en "barreras para la educación” (Salvia, 2008, p. 197), en condicionantes, también, como dijimos, son estas mismas condiciones las que les permiten seguir pensando en las posibilidades de la escuela y, por tanto, en sus posibilidades de vida a través de, como dice Deleuze (2009), su producción de-

10 Corto audiovisual presentado en el marco de la $1^{\circ}$ Feria de Ciencias Humanas y Sociales de la UNSAM de 2016. 
seante. Frente a la actual realidad social y educativa, el desafío está puesto en la pregunta por la posibilidad: la posibilidad de vivir, la posibilidad de qué hacer, tal como decía el docente en su relato, la posibilidad de producir conocimiento que reconozca el lugar de los sujetos no capturados por su negatividad sino por su potencialidad, la posibilidad de conformar identidades. El docente ubica al temor y su superación en el campo de la posibilidad. Pero este grupo de profesores entrevistados por sus propios estudiantes van más allá y diferencian los miedos individuales de los colectivos y ubican a esos temores en la relación con la impronta en las personas y con sus procesos de formación:

Hay que diferenciar entre los miedos individuales que todos tenemos. En mi caso creo que el miedo más grande es a la muerte o a una enfermedad que no pueda superarse y que te deje imposibilitado de hacer todo lo que querés hacer. Y después están los miedos colectivos que tienen que ver con las épocas, por eso van cambiando. Entonces, una cosa es el miedo colectivo en la dictadura que si vos te corrías de la norma lo pagabas con tu vida. Y eso deja una impronta. Y deja un tipo de formación en las personas que vivieron esa época que es bastante distinta de las que pasaron otras. Pero después hubo otras épocas que también generaban un miedo terrible. En el 2001 por ejemplo la gente tenía miedo de perder el trabajo. Y los que estaban desocupados no poder sobrevivir. A no poder subsistir. Por eso hay miedos colectivos y miedos individuales (Profesora, escuela secundaria, Villa Maipú, Partido de San Martín, Provincia de Buenos Aires, Septiembre de 2016).

La profesora, al igual que el otro profesor, contextualiza esos "miedos colectivos" en relación a la época. No son lo mismo los miedos de la dictadura que los de momentos de crisis como en el 2001 o como cuando se pierde el trabajo. Los miedos cargan de sufrimiento a quienes lo perciben (Salazar Pérez, 2011) y esos miedos que van cambiando dejan una impronta identitaria, según la profesora que se encarga de diferenciar los miedos individuales, más personales, de aquellos que son producto de las situaciones sociales o colectivas.

$\mathrm{Al}$ escuchar a los jóvenes sobre aquello que tienen para decir de sus vidas en sus barrios y en sus escuelas, sobre sus vidas presentes y futuras, sobre sus miedos presentes y futuros, a diferencia de los docentes, sus miedos aparecen en relación a sus propias vidas, a quedarse solas, a la violencia o a tener o no futuro, tal como ellas dicen: 
A quedarme con mi hijo sola y que me dejen sin mi mamá.

Yo le tengo miedo a que te secuestren y que te hagan prostituirse. Y que te violen porque te queda una marca en la vida.

Tener un futuro que no sea igual a cómo te lo pensaste ni nada (Estudiantes, mujeres, taller audiovisual en escuela secundaria, Jose León Suárez, Partido de San Martín, Provincia de Buenos Aires, 2011, "Las cosas como las vemos"11).

Los miedos asumen el rostro de cualquier estudiante y docente de cualquier ciudad latinoamericana o hasta del mundo, se deslocalizan. Así, quedarse sola, el secuestro y la trata, tener un futuro distinto al imaginado son los tres miedos puntuales que acontecen en las estudiantes del conurbano bonaerense pero que podrían ser estudiantes de cualquier parte. Miedos que son diferentes y trabajados de otra forma con respecto a los docentes. Estas posturas que, en la actualidad, asumen los jóvenes estudiantes en relación a los miedos de diferentes formas, son sin lugar a dudas, una forma de resistir a la idea de que la realidad no se discute ni transforma. Ya nadie les puede decir hacia dónde ir y cómo llegar, o al menos sienten y dicen eso. Volvemos a la idea que sienten y pueden ver caminos aunque no saben bien cómo lo van a realizar. Esos sentidos sobre la vida en general y la escuela en particular ya no anticipan la inevitabilidad de los destinos, el fracaso, sino que son luchas contra esa inevitabilidad. Ante esas luchas de los estudiantes, los docentes ubican los miedos en relación directa con los sueños y con las posibilidades de enfrentarlos para superarlos y poder cumplirlos:

Es muy importante la superación de los miedos para la realización de los sueños teniendo en cuenta que es el desafío. El desafío justamente para pelear por eso que uno quiere y que a veces que no son tanto miedos como límites que uno se pone. Entonces se empieza a decir yo esto no lo puedo hacer. Esto no es para mí. Porque me equivoque una vez, me equivoque dos. No supere tal prueba. O no lo intentan por miedo que les vaya mal. Eso es lo que hay que superar. Eso sí hay que superarlo porque no hay nada peor que mirar hacia atrás en el tiempo y decir no hice esto por miedo, no hice esto porque no me anime. Porque miras hacia atrás y decís que tonto perdí la oportunidad de arriesgarme. Después si te va mal o no lo podes realizarlo es otra cosa. Pero vos lo intentaste. Entonces no te queda el sabor amargo de que te quede

11 Producción audiovisual que se puede ver en https://vimeo.com/29752122 
pendiente eso en la agenda. Y que la vida es corta entonces hay que intentar hacer de todo lo que uno quiere (Profesora, escuela secundaria, Villa Maipú, Partido de San Martín, Provincia de Buenos Aires, Septiembre de 2016).

La profesora es quien les habla a los estudiantes sobre la superación de los miedos para cumplir los sueños, pelear por lo que uno quiere, intentar, enfrentar esos límites que te imponen de afuera. El miedo viene asociado a los sueños y desafíos. Si hay algo que caracteriza nuestros tiempos de crisis es, justamente, luchar por superar los miedos, vencerlos, arriesgarse, tal como afirman estas otras dos profesoras:

Pero igual seguí, no me importó. O sea los sueños están buenos tenerlos, está bueno luchar por ellos, conseguirlos y vencer los miedos. Eso es lo más importante (Directora, 8 de Septiembre de 2016, Escuela Secundaria, Villa Maipú, Partido de San Martín).

En la actualidad y bueno la verdad es que los miedos hay que enfrentarlos. Día a día. Todos los días hay que enfrentarlos y no perder la oportunidad de decir esto no lo pude hacer por miedo. No hay que paralizarse. Hay que seguir (Profesora, escuela secundaria, Villa Maipú, Partido de San Martín, Provincia de Buenos Aires, Septiembre de 2016).

También, tal como decía la docente de la cita anterior, la superación de los miedos viene de la mano de cruzar los límites que los prejuicios sociales instalan, tal como sugiere este otro profesor:

No tener miedo a lo que uno siente, porque por ahí en mi caso la música o el arte no es algo que esté muy valorado en la sociedad hoy en día. Quizás alguien quiere estudiar para ser actor, la carrera de teatro, y después te dicen vos vas a estudiar la carrera de actor y después te dicen ¿de qué vas a trabajar? (Profesor, taller audiovisual en escuela secundaria, José León Suárez, "Te daré un lápiz para que escribas tu futuro", 2014 ${ }^{12}$ ).

Este profesor asocia a la superación de los miedos por aquello que uno siente y desea en contraposición de las valoraciones sociales y ubica el interrogante en la utilidad y la función social que cada formación tiene en cada contexto social. Desde estos sentidos, se abre el debate sobre qué tipo de sa-

12 Producción audiovisual que se puede ver en https://vimeo.com/29752122 
beres prevalecen y cuáles se priorizan en la escuela y cómo se produce la transmisión de esos saberes dentro y fuera del aula atendiendo a cómo los miedos o temores de las épocas que vivimos van calando en nuestras formaciones identitarias. En todo caso, lo que queremos hacer aquí siguiendo la crítica que realiza el profesor es impugnar aquellos discursos y teorías como la del capital humano- que piensan sólo el sentido instrumental de la educación, la utilidad social de la formación y por tanto el grado de valoración de los saberes. De esta forma, son los docentes quienes perciben que los estudiantes asumen las pocas garantías que les ofrece la sociedad para su vida, visualizando un camino inestable hacia su adultez, marcado por la amenaza de la violencia, el desempleo y la pobreza.

Los problemas que percibo a nivel de los chicos es mucha falta de afecto. Muchísima falta de afecto. Van a la escuela inconsciente o conscientemente a buscar eso que les falta. No tener confianza con nadie para poder hablarlas. Tener miedo, el miedo de hacer algo, ¿entendés? que los pueda llegar a perjudicar en su salud o que los pueda llegar a marcar como... "Uh mirá lo que hizo, no tiene corazón". Los noto bastante... como se dice cuando no tenés esperanzas. Cuando no confiás en vos mismo (...) Están sumamente asustados, se sienten incapaces, y yo les dije que no hay peor fracaso que no intentarlo. El tema es no rendirse, el tema es que sepan que son capaces. Que obviamente, que ellos nacieron en un lugar donde las cosas se defienden de otra manera. ¿Entendés? Se defienden a: vamos a pararnos y esto es mío, y no te lo llevas (Profesora, Mujer, Escuela de San Andrés, Partido de San Martín, Provincia de Buenos Aires, Octubre de 2016).

Tener miedo, no buscar, no confiar, no ser capaces, estar asustados es lo que caracteriza las fuerzas jóvenes dentro y fuera de la escuela. El tema para esta profesora -y aquí quiero arriesgarme a decir para los jóvenes que viven en contextos de pobreza urbana- es intentarlo, no rendirse, defenderse. Tal como se viene sosteniendo, estas condiciones siempre suponen tensiones, grietas y posibilidades de desear. En sus relatos, los docentes le otorgan un lugar destacado tanto a lo temido como a lo esperado para los sueños y deseos. $Y$ es en este sentido que nos encontramos cotidianamente con estudiantes que expresan lo que quieren y esperan en su futuro. Un esperar que por momentos parece desesperar, desencantar y por instantes tiene un empuje esperanzador que sorprende. Parecería que hay cosas que les preocupan mucho y se animan a mostrarlas y a mostrarse junto a ellas. Hay temas que los entusiasma y los 
apasiona. Quizás, no son, necesariamente, cuestiones relevantes desde el punto de vista del espacio escolar moderno. Apuestan defendiendo sus derechos a estar en las escuelas así como a proyectar un futuro diferente en su barrio. Exigen ser iguales, tal como nos decía una estudiante “¿por qué nos tenemos que callar? Tenemos los mismos derechos", en un mundo que los condena. No se olvidan de las dificultades que enfrentan diariamente, saben que esas apuestas son difíciles ante sus condiciones de vida. Nos encontramos con los "me gustaría", "sueño" y "quiero". Estas inquietudes vuelven a poner en tensión el discurso que pesa sobre estos grupos sociales.

Los jóvenes no se "limitan" a pensar negativamente su mundo futuro, sino que, también ven sus posibilidades. Nada ni nadie les impide tener esperanzas, sueños, proyectos. A pesar de todos los miedos que circulan por sus alrededores, estas posturas que, en la actualidad, asumen los jóvenes estudiantes, de diferentes formas, es, sin lugar a dudas, una forma de resistir a la idea de que la realidad no se discute ni se transforma. Los estudiantes con los que nos encontramos son sujetos que aparecen "en el orden de otra temporalidad, futura, imaginaria y no tangible que se significan sus esfuerzos en el presente en su vínculo con la escuela" (Redondo, 2004, p. 132). Son estudiantes que, tal como dice Deleuze (2008), resisten "al presente, no para un retorno, sino a favor, eso espero, de un tiempo futuro, es decir, convirtiendo el pasado en algo activo y presente afuera, para que por fin surja algo nuevo, para que pensar, siempre, se produzca en el pensamiento" (p. 155).

\section{Conclusiones}

La relación miedos, crisis y escolaridad tienen unas particularidades para explorar y seguir haciéndolo en función de las dinámicas cotidianas que se desarrollan en las escuelas en contexto de pobreza urbana de Argentina. Ello porque esa relación expresa muchas de las singularidades de las problemáticas escolares actuales así como de las sociales. Los miedos, siguiendo a Salazar Pérez (2011) deben ser estudiados, explicitados, modificados y "hasta anulados para pensar en una mejor sociedad" (p. 27).

Tal como se describió en el texto, existen muchos miedos y cuando esos miedos se asumen dentro del espacio escolar, desalojarlos no es asunto de otros sino que es de los propios docentes junto con sus estudiantes. Tal como dice Salazar Pérez (2011): 
Cada intento de poner la lucha en la calle, revelarla ante los ojos de los demás, vincularla con otros actores afectados, invitar a autoconvocados, asumir la rebeldía como un objetivo prioritario del sujeto es la plataforma para que los miedos vuelen y salgan del subconsciente colectivo y justo ese episodio le temen los grandes potentados del mundo, se atemorizan y cargan de miedo cuando los de abajo digan ya basta (p. 30).

En todo caso la tarea cotidiana que están asumiendo los docentes con sus estudiantes es desalojar esos miedos a través de las improntas que puede tener la escuela, a través de las relaciones y de los procesos de formación que allí se desarrollan, como esperanzas y formas de estructurar los sueños venideros, para potenciar y posibilitarla construcción de futuros mejores que las condiciones de vida van demarcando.

En este recorrido, marcamos algunas diferencias y semejanzas entre las generaciones. Los jóvenes en mayor medida que los adultos de las escuelas piensan y contextualizan los miedos desde afuera de las instituciones. Otra diferencia entre unos y otros es que los docentes piensan los miedos individuales y colectivos de una forma explícita más que los estudiantes. Sin embargo, si bien nos encontramos con estudiantes que piensan y relatan los miedos en relación, fundamentalmente, a sus propias vidas, también lo hacen relación con los procesos de crisis. Así, los estudiantes como los docentes tratan de desnaturalizar los miedos, las crisis y sus formas de estar en el mundo y en la escuela.

Para finalizar, también queremos pensar en la relación entre miedo y subjetividad, o las formas particulares como se produce la subjetividad de los individuos para enfrentar el entorno, con sus dudas, incertidumbres y temores (Useche Aldana, 2012). Los miedos desarrollan nuevas formas de subjetividad (Rotker, 2000) y son estas políticas del miedo que producen experiencias de espantos que actualizan constantemente las incertidumbres y afecta los cuerpos, tanto de estudiantes como de docentes que sufren somatizando cada vez con más frecuencia. Los miedos tienen el poder de afectar a los sujetos a través de las angustias individuales y colectivas, de las amenazas permanentes, la sensación de soledad y de desconfianza (Useche Aldana, 2012). Por tanto, la potencia de los cuerpos se ven disminuidas y, tal como dice Salazar Pérez (2011), el miedo "siembra riesgos en la subjetividad de los colectivos humanos" (p. 32). Pero fundamentalmente lo que observamos es que los miedos de jóvenes y adultos en la escuela ya no anticipan la inevitabilidad de los destinos, no conllevan fracaso, sino que son luchas contra esa inevitabilidad, 
luchas que se convierten en una tarea para toda la vida enfrentándose a sus raíces (Bauman, 2014) e implican reacciones y respuestas al desarraigo porque son luchas contra la injusticia y las diversas formas de exclusión (Barbero, 2000). Los sentidos que producen docentes y estudiantes sobre los miedos se realizan conjuntamente con las posibilidades de enfrentarlos, superarlos e insistir para poder cumplir los sueños y deseos propios, se preguntan, tal como dice Rotker (2000), por las formas de cómo vencerlos, “de cuerpo a cuerpo o de cuerpo con cuerpo" (p. 22).

\section{Bibliografía}

Barbero, J. M. (2000). La ciudad entre medios y miedos. En S. Rotker (Ed), Ciudadanías del miedo (pp. 29-35). Caracas: Nueva Sociedad.

Barthes, R. (1981). Mitologías. México: Siglo XXI.

Bauman, Z. (2014). Miedo líquido. La sociedad contemporánea y sus temores. Buenos Aires: Paidós.

Benjamin, W. (1987). Dirección única. Madrid: Ed. Alfaguara.

Carpentieri, Y.; Dafunchio, S.; Langer, E. \& Machado, M. (2015). Producir saberes desde la experiencia de un Taller Audiovisual en una escuela secundaria en contexto de pobreza urbana. Novedades educativas, 294, 27-32.

Castel, R. (2004). La inseguridad social. ¿Qué es estar protegido? Buenos Aires: Manantial.

Croce, A. C. (2005). De las resistencias internas para incluir a los adolescentes y jóvenes en el sistema educativo. En M. Krichesky (Comp.), Adolescentes e inclusión educativa. Un derecho en cuestión (pp. 81-94). Buenos Aires: Ediciones Novedades Educativas.

Deleuze, G. (1994). Lógica del sentido. Barcelona: Paidos.

Deleuze, G. (2005). Derrames entre el capitalismo y la esquizofrenia. Buenos Aires: Cactus.

Deleuze, G. (2008). Foucault. Buenos Aires: Paidos.

Deleuze, G. (2009). Deseo y placer. En M. Foucault, El Yo minimalista y otras conversaciones (pp. 181-190). Buenos Aires: La marca Editora.

Duby, G. (1995). Año 1000, año 2000. La huella de nuestros miedos. Buenos Aires: Ed. Andrés Bello.

Foucault, M. (2006). Seguridad, territorio, población. Argentina: Fondo de Cultura Económica. 
Foucault, M. (2012). El poder, una bestia magnífica. Sobre el poder, la prisión y la vida. Buenos Aires: Siglo veintiuno editores.

Foucault, M. (2014). Las redes del poder. Buenos Aires: Prometeo.

Galeano, E. (2010). Patas arriba. La escuela del mundo al revés. Buenos Aires: Siglo veintiuno editores.

Glass, R. (1964). London: aspects of change. London: MacGibbon \& Kee.

Grinberg, S., \& Langer, E. (2014). Insistir es resistir. Estudiantes, dispositivos pedagógicos y pobreza urbana en tiempos de gerenciamiento. Revista del IICE, 34, 29-46.

Kaplan, C. (2012). Entrevista a FEDUBA. Por AleliJait. 12 de Octubre. Recuperado de https://goo.gl/z6N3Ur (12-10-2012).

Korstanje, M. (2010). El miedo político en Robin y Foucault. Revista de Antropología Experimental, 10, 111-132. España.

Langer, E. (2016). La construcción de confianza para el estudio de prácticas de resistencia en la escolarización de jóvenes en contextos de pobreza urbana. Revista RIIEP, 9(2), 113-137.

Redondo, P. (2004). Escuelas y pobreza. Entre el desasosiego y la obstinación. Buenos Aires: Paidós.

Reguillo, R. (1996). Los lenguajes del miedo ¿Nuevos escenarios, nuevos? Renglones, 35, 69-74.

Reguillo, R. (2000). Emergencia de culturas juveniles. Estrategias del desencanto. Bogotá: Norma.

Rotker, S. (2000). Ciudadanías del miedo. Caracas: Editorial Nueva Sociedad.

Salazar Pérez, R. (2011). Los miedos ocultos en la sociedad del siglo XXI. Theomai, 23, 24-34.

Salvia, A. (2008). Jóvenes promesas. Trabajo, educación y exclusión social de jóvenes pobres en la argentina. Buenos Aires: Ed. Miño y Dávila.

Sennett, R. (2000). La corrosión del carácter. Las consecuencias personales del trabajo en el nuevo capitalismo. Barcelona: Anagrama.

Spinoza, B. (1980). Ética demostrada según el orden geométrico. Madrid: Ediciones Orbis S. A. Hispamerica.

Useche Aldana, O. (2008). Miedo, seguridad y resistencias: el miedo como articulación política de la negatividad. Polis, 19. Recuperado de https://goo. gl/2bSxT7 (27-09- 2017).

Fecha de recepción: 2017/II/08; fecha de aceptación: 2018/02/05;

\section{fecha de publicación: 2018/03/0I}

